\title{
Lymphocytic sialadenitis in the major and minor glands: a correlation in postmortem subjects
}

\author{
D. M. CHISHOLM, J. P. WATERHOUSE, AND D. K. MASON \\ From the Department of Oral Medicine and Pathology, University of Glasgow Dental Hospital \\ and School, Glasgow, Scotland, and the Department of Oral Pathology, University of Illinois, \\ Chicago, USA
}

SYNOPSIS In the present investigation, the prevalence of focal lymphocytic adenitis in th\& submandibular salivary gland was observed in a series of 116 postmortem subjects aftep suitable exclusions had been made. Focal lymphocytic adenitis could not be demonstrate in the labial salivary glands. The degree of lymphocytic infiltration in the labial salivary gland $\vec{\delta}$ is positively correlated with the level of focal lymphocytic adenitis in the submandibulaP

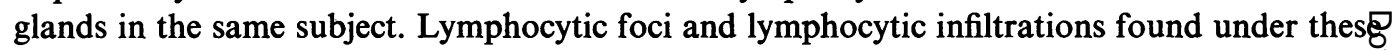
circumstances are probably related. This finding provides conceptual support for the examinas tion, by biopsy, of the labial glands in patients suspected of Sjögren's syndrome.

The aim of the present study was to investigate the prevalence and degree of lymphocytic sialadenitis in the submandibular and minor labial glands in a series of postmortem subjects. Waterhouse (1963) has shown that the changes observed in the submandibular gland in the postmortem subject reflect the degree of focal adenitis present in the parotid and lacrimal glands. Furthermore, Waterhouse and Doniach (1966) have provided strong evidence for the association of focal lymphocytic sialadenitis and rheumatoid arthritis and have suggested that this lesion may represent a focal manifestation of the lesion in Sjögren's syndrome. Recently, Chisholm and Mason (1968) have shown focal lymphocytic adenitis of the labial salivary glands to be a consistent finding in patients with Sjögren's syndrome. In view of these findings, therefore, we felt that it would be of value to observe and correlate the changes noted in the submandibular and labial salivary glands for each subject in a postmortem series of over 100 subjects.

\section{Materials and Methods}

A submandibular salivary gland and an ellipse of oral mucosa and subjacent tissue down to the

Received for publication 26 March 1970. muscle layer of the lower lip were excised at necropsy. Tissue was obtained from necropsie? at the Bernhard Baron Institute of Pathology, London Hospital, and the University Depar ment of Pathology, Royal Infirmary, Glasgow between March and June 1967. They were take? from all necropsies on fixed days of the weets excepting a few not obtainable for administrative reasons.

The necropsy material was fixed in $10 \%$ formalin, and routine paraffin sections, staine with haematoxylin and eosin, were prepareds Each submandibular gland and each ellipse of. oral mucosa was bisected so that a large represen tative histological section would be obtained. The total number of cases examined was 128 and, of these, 13 were excluded for the reasonł given below, leaving 116 cases admitted to tho present series. The histological assessment was done independently by three observers.

\section{Criteria of Exclusion}

Before a gland was included in the series, the following criteria, designed to exclude infection and neoplasm as effective causes of pathological change, were applied. Gland lobules were accep table if they were free from duct dilatation 
indicating obstruction to flow of secretion, and were free from extravascular polymorphonuclear leucocytes. These pathological changes, when present, were not infrequently limited to isolated lobules. Glands were acceptable if a representative section of the gland (approximately $4 \mathrm{sq} \mathrm{cm}$ for the submandibular and $4 \mathrm{sq} \mathrm{mm}$ for the labial) remained after exclusion of abnormal lobules.

Cases were admitted to the series if they were free from neoplasm of lymphocyte-like calls, and had not received cytotoxic drugs withın the last three months before death. Leukaemia patients were excluded altogether.

The 13 exclusions comprised seven with autolysis of gland parenchyma, and therefore not suitable, one with neoplastic material present in the ducts, and five with extravascular polymorphonuclear leucocytes, together with duct dilata. tion.

\section{Criteria of Focal Lymphocytic Adenitis}

A 'focus' was defined as one consisting of an aggregate of 50 or more lymphocytes and histiocytes, usually with a few plasma cells placed peripherally, adjacent to and apparently replacing

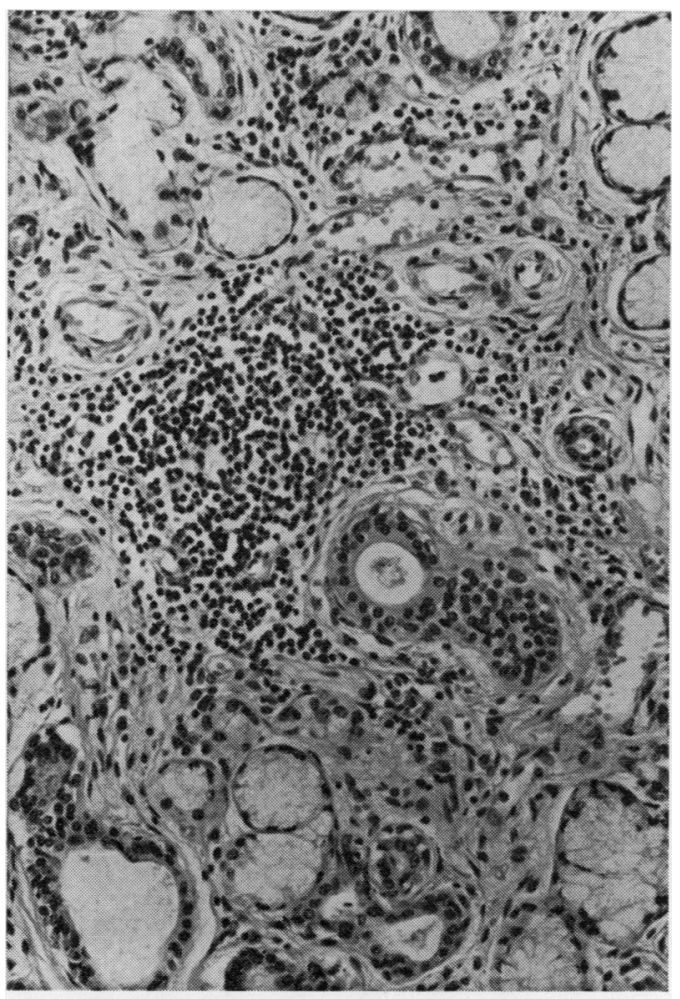

Fig. 1 A focus of lymphocytes around a small duct of a submandibular salivary gland. $H \& E \times 282$ gland acini (Fig. 1). Such foci are commonly $\frac{\varrho}{\overline{5}}$ found in relation to small veins and at the edge 0 of intralobular ducts (Waterhouse and Doniach, $\stackrel{\oplus}{*}$ 1966).

The grading standard used for the submandibular gland is shown in Table I.

In order to standardize the area examined and $\bar{C}$ record the degree of histopathological change, 을 the grading standard shown in Table II was $\frac{\bar{\omega}}{\overrightarrow{ }}$ employed for the labial salivary glands. All $\stackrel{\mathbb{\complement}}{\complement}$ minor salivary gland tissue in the sections was

\begin{tabular}{llc}
\hline Grade & Lymphocytic Foci /4 sq cm of Salivary Tissue \\
\hline 0 & None & $0-1$ \\
1 & 'Slight' & $2-8$ \\
2 & 'Moderate' & $9-40$ \\
3 & 'Severe' & $40+$ \\
4 & 'Very Severe' & $>$ half gland parenchyma replaced \\
\hline
\end{tabular}

Table I Grading standard for submandibular gland

\begin{tabular}{ll}
\hline Grade & $\begin{array}{l}\text { Lymphocytic Infiltration or Foci/sq } \mathrm{mm} \\
\text { of Salivary Tissue }\end{array}$ \\
\hline 0 & Absent \\
1 & Slight infiltrate \\
3 & Moderate infiltrate \\
4 & One focus \\
& More than one focus
\end{tabular}

Table II Grading standard for labial glands

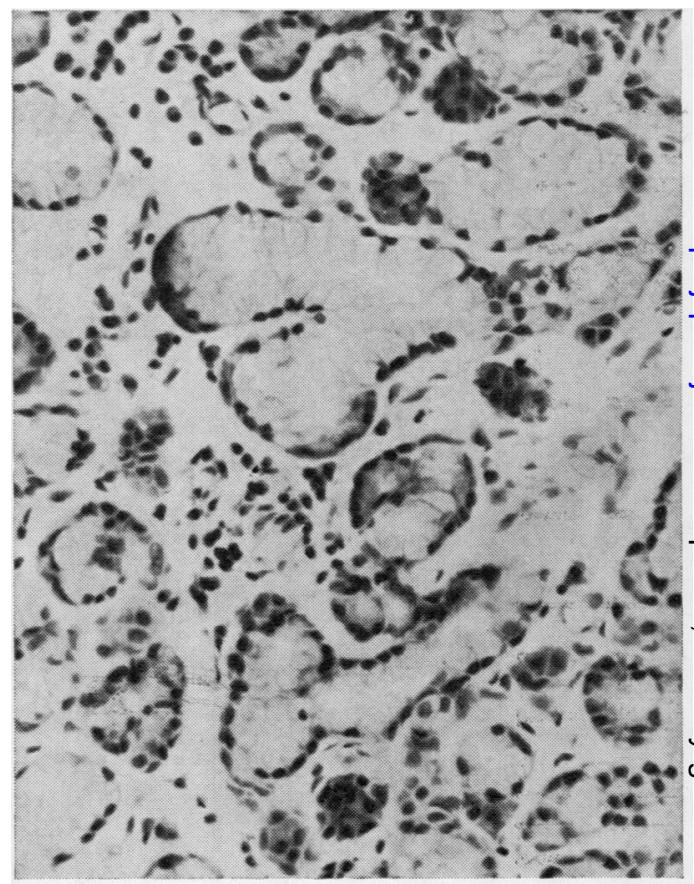


examined and scanned for the presence of lymphocytic foci and/or diffuse lymphocytic infiltration. The degree of lymphocytic infiltration and/or number of foci were expressed as a value per $4 \mathrm{sq} \mathrm{mm}$ of minor salivary tissue.

An example of moderate lymphocytic infiltration (grade 2) in the minor glands is illustrated in Figure 2.

The level of correlation between the grade of focal lymphocytic adenitis in the submandibular gland and the degree of lymphocytic infiltration in the labial glands of each subject was computed as the non-parametric Spearman rank correlation coefficient applying the correction for tied ranks, and a significance test was carried out (Siegel, 1956). The non-parametric correlation coefficient was used in order to avoid the assumption that the data were normally distributed.

\section{Results}

SUBMANDIBULAR GLANDS

The figures for the prevalence of focal lymphocytic submandibular sialadenitis found in 56 female and 60 male subjects are given in Tables III, V, VI, and IX and Figure 3. In this series of 116

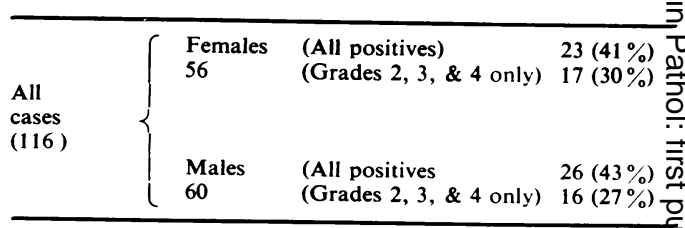

Table III Prevalence of focal lymphocvtic adenitis (submandibular gland)

All
cases
$(116)$$\quad\left\{\begin{array}{lll}\text { Females } & \begin{array}{l}\text { (All positives) } \\ \text { (Grade 2) }\end{array} & 31(55 \%) \\ & & \\ \text { Males } & \text { (All positives) } & \\ 60 & \text { (Grade 2) } & 39(65 \%) \\ 12(20 \%)\end{array}\right.$

Table IV Prevalence of slight or moderate lymphocytic infiltration of labial gland

\begin{tabular}{|c|c|c|c|c|c|c|}
\hline \multirow{2}{*}{$\begin{array}{l}\text { Age in } \\
\text { Years }\end{array}$} & \multicolumn{4}{|c|}{ No. with Grade of Severity } & \multirow[t]{2}{*}{ Total } & \multirow{2}{*}{$\begin{array}{l}\text { Percentage } \\
\text { Positive }\end{array}$} \\
\hline & 0 & 1 & 2 & 3 & & \\
\hline $0-44$ & 7 & 2 & 1 & 0 & 10 & 30 \\
\hline $45-64$ & 12 & 1 & 5 & 3 & 21 & 43 \\
\hline $65+$ & 14 & 3 & 6 & 2 & 25 & 44 \\
\hline Total & 33 & 6 & 12 & 5 & 56 & 41 \\
\hline
\end{tabular}

Table V Numbers of females with submandibular lymphocytic sialadenitis
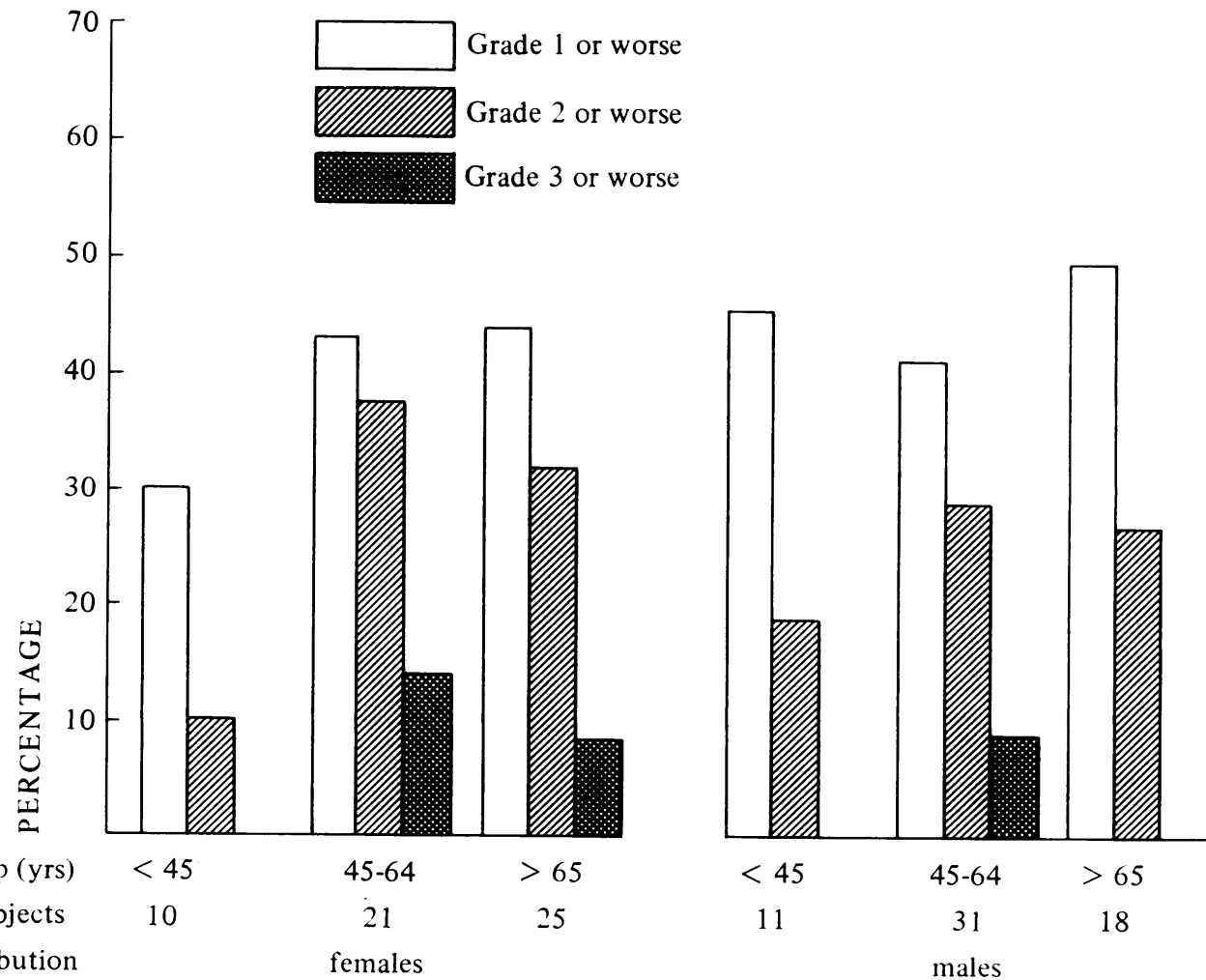

Fig. 3 The prevalence of lymphocytic submandibular sialadenitis in males and females. 
subjects the frequency of involvement by sialadenitis is not significantly different in males or females. This is so, either when all degrees of sialadenitis $\left(\chi^{2}=0.003, \mathrm{P}=\right.$ greater than 0.5$)$, or when moderate and severe degrees of sialadenitis $\left(\chi^{2}=0.05, P=\right.$ greater than 0.5$)$ are considered. Affected glands occur in the three age groups listed (Tables V and VI and Figure 3). A tendency for more severe degrees to occur in females aged 45-64 appears in Table V and Fig. 3 , but numbers in the groups are too small for a formal test of significance to be carried out.

\section{LABIAL GLANDS}

The figures for the prevalence of lymphocytic infiltration of the labial salivary glands (the exclusions quoted above having been made) are given in Tables IV and IX and Figure 4.

The frequency of involvement of the glands in males or females is not significantly different, either when all grades of severity $\left(\chi^{2}=0 \cdot 8\right.$, $\mathbf{P}=$ greater than 0.05 ) or when moderate degrees only $\left(\chi^{2}=0.2, \mathbf{P}=\right.$ greater than 0.05$)$ are considered. A fractionally higher proportion of slightly, and also of moderately, involved glands is found in females between 45 and 64 years by contrast with other age groups in males or females (Tables VII and VIII and Figure 4). The difference

\begin{tabular}{lrrrrrl}
\hline $\begin{array}{l}\text { Age in } \\
\text { Years }\end{array}$ & \multicolumn{3}{c}{ No. with Grade of Severity } & Total & $\begin{array}{l}\text { Percentage } \\
\text { Positive }\end{array}$ \\
\cline { 2 - 5 } & \multicolumn{1}{c}{0} & 1 & 2 & 3 & & \\
\hline $0-44$ & 6 & 3 & 2 & 0 & 11 & 45 \\
$45-64$ & 18 & 4 & 6 & 3 & 31 & 42 \\
$65+$ & 9 & 4 & 5 & 0 & 18 & 50 \\
Total & 33 & 11 & 13 & 3 & 60 & 43 \\
\hline
\end{tabular}

Table VI Numbers of males with submandibular lymphocytic sialadenitis

\begin{tabular}{lccccc}
\hline $\begin{array}{l}\text { Age in } \\
\text { Years }\end{array}$ & \multicolumn{2}{l}{ No. with } & Grades of Severity & Total & $\begin{array}{l}\text { Percentage } \\
\text { Positive }\end{array}$ \\
\cline { 2 - 4 } & 0 & 1 & 2 & & \\
\hline $0-44$ & 8 & 1 & 1 & 10 & 20 \\
$45-64$ & 6 & 9 & 6 & 21 & 71 \\
$65+$ & 11 & 7 & 7 & 25 & 56 \\
Total & 25 & 17 & 14 & 56 & 55 \\
\hline
\end{tabular}

Table VII Numbers of females with lymphocytic infiltration of the labial glands

\begin{tabular}{lrrrrl}
\hline $\begin{array}{l}\text { Age in } \\
\text { Years }\end{array}$ & \multicolumn{2}{l}{ No. with } & Grade of Severity & Total & $\begin{array}{l}\text { Percentage } \\
\text { Positive }\end{array}$ \\
\cline { 2 - 4 } & \multicolumn{1}{c}{0} & 1 & 2 & & \\
\hline $0-44$ & 5 & 3 & 3 & 11 & 54 \\
$45-64$ & 10 & 17 & 4 & 31 & 68 \\
$65+$ & 6 & 7 & 5 & 18 & 67 \\
Total & 21 & 27 & 12 & 60 & 65 \\
\hline
\end{tabular}

Table VIII Numbers of males with lymphocytic infiltration of the labial glands

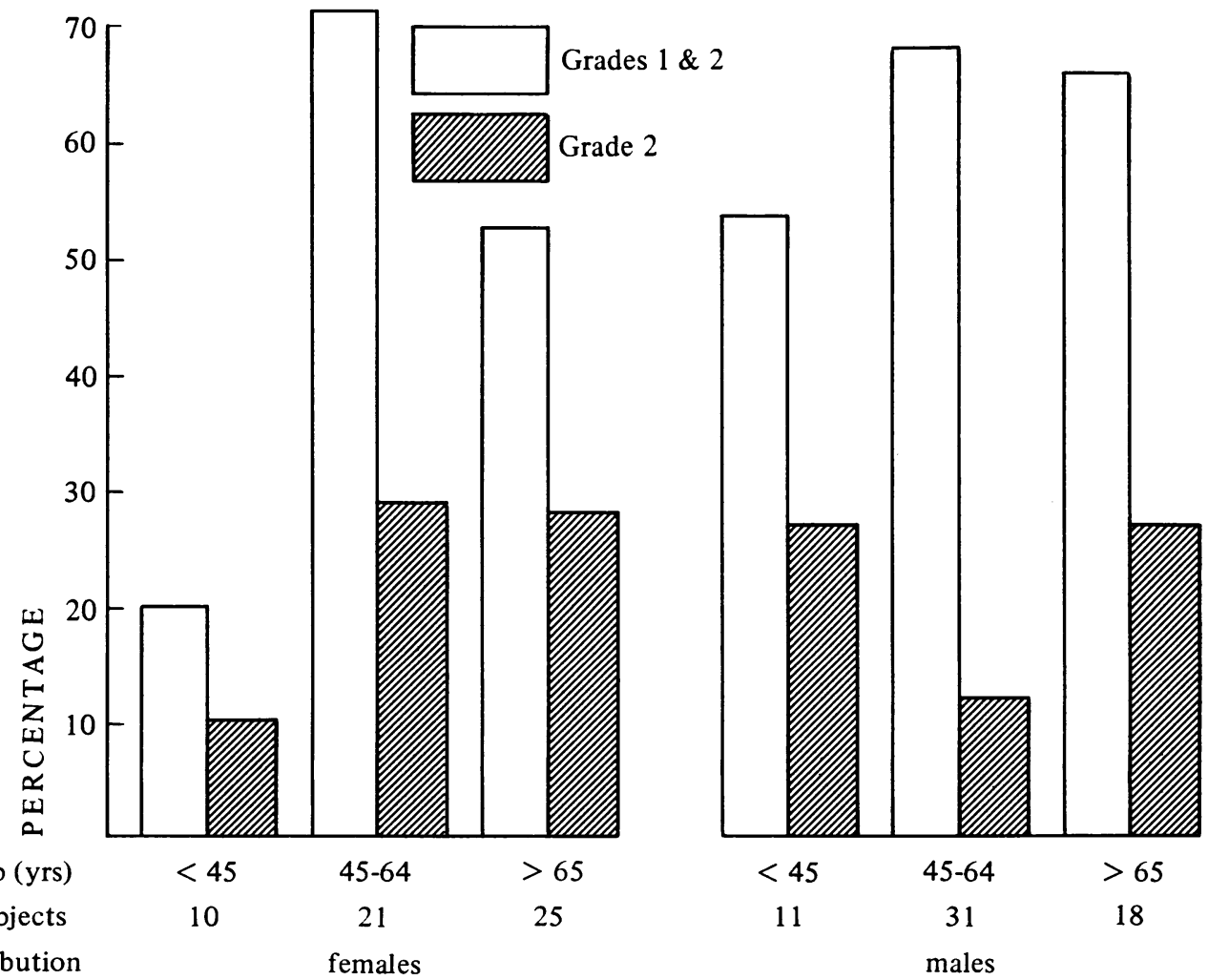

Fig. 4 The prevalence of lymphocytic labial sialadenitis in males and females. 
does not approach statistical significance (see, however, Discussion below).

In none of the labial glands were foci of lymphocytes observed.

\section{CORRELATION BETWEEN FINDINGS IN} SUBMANDIBULAR AND LABIAL GLANDS The gradings in the submandibular and labial glands for each subject (Table IX) positively correlated. The non-parametric Spearman rank correlation coefficient $\left(r_{s}\right)$ has the value 0.32 which, for a sample size of 116 is significant at the level $P=$ less than $0.001 \quad\left(t_{114}=3.6\right)$. In view of the low level of $P$, there can be little doubt of the significance of the result, despite the modest number of grades of severity $(0,1$, and 2) of adenitis of labial glands and the correspondingly high number of tied observations. The correction for tied observations was applied as stated above and the effect of them is not great (Siegel, 1956).

If the labial glands only of this group had been examined and graded in the manner described, of the 116 subjects for whom the material met the criteria for acceptance in the series, one with a grade 3 ('severe') submandibular gland would have been graded as 0 ('normal') on the grounds of his normal labial gland (Table IX).

\begin{tabular}{lrrrrrr}
\hline Grade & \multicolumn{2}{l}{ Submandibular } & & & Total \\
\cline { 2 - 5 } & 0 & 1 & 2 & 3 & 4 & \\
\hline Labial & & & & & & \\
0 & 31 & 5 & 9 & 1 & 0 & 46 \\
1 & 31 & 5 & 6 & 2 & 0 & 44 \\
2 & 5 & 6 & 10 & 4 & 1 & 26 \\
3 & 0 & 0 & 0 & 0 & 0 & 0 \\
4 & 0 & 0 & 0 & 0 & 0 & 0 \\
Total & 67 & 16 & 25 & 7 & 1 & 116 \\
\hline
\end{tabular}

Table IX Numbers of subjects showing various combinations of submandibular and labial gland lesions

\section{Discussion}

The necropsy results confirm the work of Waterhouse and Doniach (1966) in showing the high prevalence of focal lymphocytic adenitis in the submandibular gland. As they have suggested, it may be that these changes represent a potential rheumatoid state in these subjects, since they have shown strong evidence of an association between moderate focal adenitis of the submandibular salivary gland and rheumatoid arthritis in the postmortem subject.
A fractionally higher frequency of slight $(71 \%)$ or of moderate degrees $(29 \%)$ of lymphocytic infiltration of labial glands in females between $45^{\circ}$ and 64 years than in other groups of either sex으. was found (see Results). The difference between these values and the values in other groups does? not approach statistical significance. The finding is, however, of interest in view of the predilection for middle-aged female subjects of both foca lymphocytic submandibular sialadenitis and the comparable focal lymphocytic thyroiditis thates was found in a larger earlier series (Waterhouseand Doniach, 1966). Both focal lymphocytic sialadenitis and focal lymphocytic thyroiditis may $\vec{\omega}$ be evidence of a general disturbance of the immunological system.

Lymphocytic foci were not demonstrated in this series in the labial salivary glands. This stronglyoo suggests that lymphocytic foci do not normallys occur in these glands.

The significant degree of correlation between lymphocytic infiltration in the labial salivary glands and focal lymphocytic submandibularo sialadenitis, and the presence of lymphocytic fock in labial glands in Sjögren's syndrome, suggests that the minor glands in fact reflect salivary gland@ involvement as a whole and that lymphocytic infiltrations and lymphocytic foci are related to each other. This is of importance in the investigation of disease such as Sjögren's syndrome. The biopsy necessary to obtain direct histopathological evidence of minor labial, as opposed too major, salivary gland involvement involves onlyo a trivial surgical procedure and avoids any danger of the complication of salivary fistula.

The writers acknowledge with pleasure the generous provision of facilities by Professor $I$ Doniach, Professor of Morbid Anatomy, the London Hospital Medical College, and Professon. T. Symington, Professor of Pathology, Universityo of Glasgow. One of them (JPW) wishes further to thank Professor A. E. W. Miles, Professor of Oral Pathology and Histology, L.H.M.C., in? whose department part of the work was carriedo out. The recent work of J.P.W. was supported by US PHS grant FR 5309.

References biopsy in Sjögren's disease. J. clin. Path., 21, 656-660.

Siegel, S. (1956). Nonparametric Statistics for the BehavioraE Sciences, p. 206. McGraw, Hill, New York.

Waterhouse, J. P. (1963). Focal adenitis in salivary and lacrim? glands. Proc. roy. Soc. Med., 56,911-918.

Waterhouse, J. P., and Doniach, I. (1966). Post-mortem prevalenceof focal lymphocytic adenitis of the submandibular salivary gland. J. Path. Bact., 91, 53-64. 